\title{
HISTÓRICO DA INCLUSÃO ESCOLAR: UMA DISCUSSÃO ENTRE TEXTO E CONTEXTO
}

\author{
Marasella del Cármen Silva Rodrigues Macedo ${ }^{1}$ \\ Deusodete Rita Silva Aimi \\ Iracema Neno Cecilio Tada \\ Ana Maria de Lima Souza \\ Universidade Federal de Rondônia, Porto Velho-RO, Brasil
}

\begin{abstract}
RESUMO. Este artigo aborda a temática da inclusão e sua relação com o contexto escolar a partir de um estudo teórico, buscando aproximações com o Materialismo Histórico-Dialético. Inicialmente expõe-se a constituição histórica dos movimentos sociais nacionais e internacionais com vistas à defesa dos direitos humanos. Em seguida discute-se a institucionalização do acesso e permanência da pessoa com deficiência nos sistemas escolares e as práticas atuais de exclusão nos contextos social e escolar. Finalmente, apresentam-se algumas reflexões sobre possíveis contribuições da Psicologia Escolar crítica para a diminuição do preconceito e da discriminação, possibilitando o oferecimento de educação de qualidade a todos, sem distinção. Como resultado, detectou-se a importância de estabelecer coletivamente estratégias para superar as limitações surgidas no cotidiano escolar que envolvem a informação e formação de novos posicionamentos que sejam realmente inclusivos.
\end{abstract}

Palavras-chave: Inclusão escolar; ambiente escolar; Psicologia Escolar.

\section{HISTORY OF SCHOOL INCLUSION: A DISCUSSION BETWEEN TEXT AND CONTEXT}

ABSTRACT. This paper raises the issue of inclusion and its relationship with the school context from a theoretical study, seeking approaches to historical and dialectical materialism. Initially it exposes the historical background of national and international social movements with a view to protecting human rights. Then it discusses the institutionalization of access and retention of people with disabilities in school systems and the current practices of exclusion in the social and educational environment. Finally it presents some reflections and possible contributions of critical School Psychology in order to reduce prejudice and discrimination, enabling the delivery of quality education to everybody without distinction. As a result it was found the importance of establishing collective strategies to overcome the limitations that arise at school daily routine, which involves information and formation of new ideas that are really inclusive.

Keywords: School nclusion; school environment; School Psychology.

\section{HISTORIA DE LA INCLUSIÓN ESCOLAR: UNA DISCUSIÓN ENTRE TEXTO Y CONTEXTO}

RESUMEN. Este artículo trata de la temática de la inclusión y su relación con el contexto escolar a partir de un estudio teórico, buscando aproximaciones con el materialismo histórico-dialéctico. Inicialmente se expone la construcción histórica de los movimientos sociales nacionales e internacionales para llegar a la defensa de los derechos humanos. En seguida, se discute la institucionalización de acceso y permanencia de la persona con discapacidad en los sistemas escolares y en las prácticas actuales de exclusión en el contexto social y escolar. Finalmente se presentan algunas reflexiones sobre posibles contribuciones de la Psicología Escolar crítica para la disminución del prejuicio y de la discriminación, posibilitando que se ofrezca una educación de calidad a todos sin distinción. Como resultado fue

1 Endereço para correspondência: Travessa Jesus Bulamarque Hosanah, 3743, Bairro Liberdade, CEP: 76.803-843, Porto Velho-RO, Brasil. E-mail: marasella@gmail.com. 
detectada la importancia del establecimiento colectivo de estrategias para la superación de las limitaciones encontradas en el cotidiano escolar y que involucran la información y la formación de nuevas posiciones que sean verdaderamente inclusivas.

Palabras-clave: Inclusión escolar; ambiente escolar; Psicología Escolar.

Pretendemos com este artigo abordar a temática da inclusão e sua relação com o contexto escolar, discutindo - por meio de um estudo teórico e a partir de uma aproximação no campo do Materialismo Histórico-Dialético como os ideais e limitações construídos historicamente têm contribuído para as práticas de exclusão.

A constituição de uma sociedade justa, igualitária e equitativa é reconhecida como principal finalidade da Educação, na proposta de formar cidadãos críticos e responsáveis, conscientes de seus direitos, deveres e oportunidades, a fim de poderem conviver com dignidade, preparados para o mundo do trabalho e a prática social, conforme preconiza o artigo $2^{\circ}$ da Lei de Diretrizes e Bases da Educação Nacional - LDB n. 9394/96. Não obstante, a concretização destes princípios é dificultada por fatores políticos, sociais, econômicos e, sobretudo, históricos e culturais, que por vezes impedem que a inclusão seja consolidada em nossas escolas.

Pensar a inclusão escolar nos remete à questão da diversidade humana que invariavelmente ocorre, pois, a despeito de termos garantidos direitos iguais, somos diferentes em anseios, características, pretensões, capacidades e necessidades, que devem ser respeitadas e contempladas em todos os processos de convivência social e principalmente na formação da pessoa em instituições educacionais. Por outro lado, não somos seres cuja individualidade se constitua isolada dos outros indivíduos. Duarte (2013) esclarece que é na relação entre a apropriação e a objetivação realizadas pelo gênero humano e pala mediação de outros seres humanos que se constitui a individualidade, e conclui que a apropriação dos bens culturais e históricos objetivados se constitui a partir da relação do homem com o gênero humano. Por esta forma, as forças sociais saem do âmbito imediato "emsi" e passam ao plano das forças genéricas "para-si" por meio das forças sociais elaboradas coletivamente (p. 242).

O autor lembra que, frequente $e$ equivocadamente, tem-se adotado a apropriação como processo de interiorização individualizada das objetivações humanas, porém os indivíduos se apropriam tanto das formas de objetivação transformadoras quanto das alienadas.

As instituições refletem em seu funcionamento a estrutura da sociedade complexa e contraditória, consolidada em ideais individualizantes, caracterizados pela dominação de elites que desde tempos imemoriais suplantam os interesses populares em nome da acumulação de riquezas. Carvalho e Martins (2011) corroboram esta afirmação quando asseveram que a passagem da Idade Média para o início da sociedade moderna foi marcada pela mudança nos alicerces econômicos do Império e do Papado, cujo abalo foi determinado pela ascensão da burguesia como classe econômica dominante em sua luta por ideais de liberdade individual.

A liberdade neste caso está vinculada ao que cada indivíduo pode produzir, comercializar e consumir dentro do sistema capitalista. Às pessoas que não possuem potencial produtivo sobram a assistência, a caridade e a compaixão. É esta a perspectiva adotada no contexto das iniciativas de atenção às pessoas com deficiência, criando-se o conceito de inclusão.

Como afirmam Carvalho e Martins (2011, p. 25), “... efetivamente, não existe ninguém excluído, isto é, que exista fora da sociedade e que necessite ser nela incluído." (itálicos dos autores). Prosseguem defendendo que este é um reflexo da alienação à qual os homens estão submetidos em relação ao patrimônio humano genérico. A alienação está relacionada à naturalização do fenômeno da exclusão pautada nas anomalias físicas e mentais, vistas de maneira reducionista e em desconsideração às múltiplas determinações impostas pela sociedade capitalista.

Com base nas afirmações dos autores, podemos afirmar que a inclusão é um reflexo da alienação à qual os homens estão submetidos na sociedade capitalista e representa a naturalização do fenômeno da exclusão pela via das anomalias, pois, se todos são partícipes da sociedade, o que há são formas marginalizadas de exclusão, ocasionando a necessidade de 
incluir aqueles que não condizem com o que se almeja para o indivíduo produtivo.

Por esta forma, a inclusão se apresenta de maneira paradoxal, pois, apesar de ser um tema atualmente configurado nos sistemas escolares e nos documentos legais como de responsabilidade de todo o sistema educacional, o que percebemos em nossa experiência como educadoras e agentes da história social, sobretudo em relação a pessoas com deficiência, é o preconceito, uma vez que os gestores, os educadores, as famílias e demais atores sociais argumentam que inclusão é de responsabilidade da Educação Especial. Cabe salientar que as crenças em relação ao tema foram, da mesma forma, construídas historicamente.

Tradicionalmente, esta modalidade se organizou como Educação Especial com base em práticas terapêuticas, sustentadas por diagnósticos que definiriam o atendimento a ser prestado a pessoas com deficiência. Atualmente, a Educação Especial é uma modalidade de ensino transversal, que deve perpassar todos os níveis, não devendo funcionar como um sistema paralelo. É uma estratégia de apoio a todo o sistema educacional, que deve contribuir para a aprendizagem dos alunos e não ser mais um meio de segregação, como nos mostra Tada (2009) quando afirma que alguns gestores adotam a separação de alunos com deficiência em classes especiais na perspectiva de inclusão escolar, mas os saberes transmitidos em tais classes não são os mesmos das classes regulares, pois não promovem a interação entre os alunos ditos normais, promovendo 0 preconceito em relação àqueles julgados como incapazes e anormais. A inclusão somente ocorrerá quando os saberes forem igualmente compartilhados por todos os alunos ocupando a mesma sala de aula.

As práticas excludentes continuam a prevalecer no interior das escolas, muitas vezes apoiadas em concepções de pessoas que não acreditam na capacidade humana de superar suas eventuais deficiências e nas possibilidades de cada ser de contribuir com a consolidação de uma sociedade que seja mais solidária e busque criar condições de avaliar criticamente as suas demandas, mesmo que para isso tenha que superar as muitas contradições que a constituem.

A deficiência não abarca apenas indivíduos isolados, mas pressupõe o envolvimento de pessoas e grupos em processo de reflexão acerca dos conflitos sociais e depende da necessidade de analisar coletivamente a própria sociedade.

Algumas concepções da Psicologia e da Educação se pautam pelo modelo biológico para explicar a relação entre o homem e o meio, porém o gênero humano não se constitui apenas em bases biológicas, mas sim, a partir da conjunção entre natureza e cultura (Duarte, 2013).

Neste sentido, pensar a deficiência exige analisar todos os condicionamentos que envolvem a relação "homem-mundo" e considerar os modos de produção que constituem essa relação, como é o caso da própria exploração do homem pelo homem, característica primaz do ideário capitalista.

\section{INSTITUCIONALIZAÇÃO DO ACESSO E PERMANÊNCIA: TEXTO}

Para a compreensão da inclusão escolar é necessário perscrutar a sua origem, que pode ser explicada por meio dos três paradigmas da Educação Especial: institucionalização, serviços e suportes, conforme mostraremos a seguir, com base em Aranha (2004).

De início a deficiência foi considerada um fenômeno metafísico, determinado pela possessão demoníaca ou pela escolha divina da pessoa para purgação dos pecados de seus semelhantes. Séculos da Inquisição católica e, posteriormente, da rigidez moral e ética da Reforma Protestante, contribuíram para que as pessoas com deficiência fossem tratadas como a personificação do mal, portanto, passíveis de castigos, torturas e mesmo de morte.

Com o avanço da medicina a deficiência passou a ser considerada como doença, o que fundamentou o paradigma da institucionalização, que consistia em afastar as pessoas com deficiência do convívio social, internando-as para receber cuidado, atenção e tratamento médico. Esta prática vigorou por aproximadamente oito séculos, permanecendo até os anos 50 do século XX (Aranha, 2004).

Impulsionados pelas grandes guerras e pela Declaração dos Direitos Humanos em 1948, movimentos sociais foram se organizando, e nos anos 60 e 70 novos modelos surgiram no sentido de reabilitar as pessoas normalizando-as para o convívio em sociedade, concepção que foi 
denominada de Paradigma dos Serviços (Aranha, 2004).

A partir da década de 80 o modelo emergente foi o Paradigma dos Suportes, devido ao surgimento de mais avanços na medicina e outros de ordem técnico-científica, os quais ocasionaram a quebra das barreiras geográficas, permitindo processos de comunicação mais acelerados e ainda a luta pelos direitos humanos na busca pela valorização da diversidade enquanto processo de humanização como fator enriquecedor da sociedade (Aranha, 2004).

$O$ endividamento com a edificação de preceitos educacionais inclusivos contou com uma série de movimentos sociais nacionais e internacionais, dos quais resultaram documentos significativos, dentre estes a própria Declaração Universal dos Direitos Humanos (1948), anteriormente citada. Esta Declaração não diferencia características físicas, intelectuais, nação, credo, orientação sexual, condição social ou opinião política, portanto garante às pessoas com deficiência os mesmos direitos concedidos aos demais.

A Declaração de Jomtien (1990), resultado da Conferência Mundial sobre Educação para Todos, realizada em Jomtien, Tailândia, reforça entre os países participantes a educação como direito fundamental de todos, devendo esta ser tida como imprescindível para a melhoria do índice de desenvolvimento humano $O$ documento orienta os países signatários para o nivelamento de ações que assegurem às suas populações educação com qualidade, sobretudo àqueles menos desenvolvidos.

Segundo Aranha (2004), quando os representantes brasileiros participantes da Conferência assinaram a referida Declaração "o Brasil assumiu, perante a comunidade internacional, o compromisso de erradicar o analfabetismo e universalizar 0 ensino fundamental no país" (p. 16).

O estabelecimento destes propósitos suscitou mobilizações para sua implantação e principalmente para discutir ações para educação de alunos com necessidades educacionais especiais. O resultado foi a realização da Conferência Mundial sobre Necessidades Educativas Especiais: Acesso e Qualidade, realizada pela UNESCO na Espanha, cujo documento final foi a Declaração de Salamanca (1994). Desse evento participaram 92 países e 25 organizações internacionais, e nele se reafirmou o direito à educação de todos, conforme inscrito na Declaração Universal dos Direitos Humanos, em 1948. Renovou-se também a garantia dada pela comunidade mundial em Jomtien, em 1990, de assegurar esse direito, independentemente das diferenças individuais, e foram relembradas as Declarações das Nações Unidas com ênfase nas Normas das Nações Unidas sobre a Igualdade de Oportunidades para as Pessoas com Deficiência, proclamadas em 1993, "as quais exortam os Estados a assegurar que a educação das pessoas com deficiência faça parte integrante do sistema educativo (1994)."

A Declaração de Salamanca reconhece a importância do envolvimento crescente dos governos, dos grupos de pressão, dos grupos comunitários e de pais, e, em particular, das organizações de pessoas com deficiência, na luta por melhores condições de acesso da pessoa com deficiência a uma educação de qualidade. Este envolvimento político é um aspecto que ressaltamos como fator primordial para o desenvolvimento de uma sociedade e para a melhoria da qualidade de vida de sua população. Entendemos que os direitos são concedidos a todos, portanto a causa das pessoas com deficiência é também uma luta de todos.

Entre os principais ganhos advindos da Declaração de Salamanca destacam-se o respeito à diversidade e a garantia de acesso e permanência das pessoas com deficiência no sistema educativo de ensino regular, além da incitação aos governos para a elaboração de políticas públicas que tenham como fim a educação inclusiva.

A participação do Brasil em discussões, acordos e movimentos internacionais suscitou ações e documentos legais que passaram a orientar as políticas públicas para o atendimento de alunos com deficiência com vistas a uma sociedade mais inclusiva, entre os quais estão a Constituição Federal (1988). A Carta Magna é um símbolo importante de democratização do País e avocou os princípios da Declaração dos Direitos Humanos, os quais estão inscritos no seu artigo $5^{\circ}$, o qual estabelece, sem qualquer distinção, o direito "à vida, à liberdade, à igualdade, à segurança e à propriedade" de todas as pessoas que residem no país (Brasil, 1988).

A Constituição promoveu ainda a descentralização dos recursos da União para que Estados e Municípios trabalhem conforme 
as suas prioridades, manifestando os ideais democráticos da população na atenção às necessidades locais.

O Estatuto da Criança e do Adolescente (1990) é outro documento cujo advento reafirmou o compromisso de proteção integral à criança e ao adolescente. O ECA, em seu artigo $3^{\circ}$, estabelece que sejam respeitados os seus direitos e deveres individuais e coletivos, "... assegurando-se-lhes, por lei ou por outros meios, todas as oportunidades e facilidades, a fim de Ihes facultar o desenvolvimento físico, mental, moral, espiritual e social, em condições de liberdade e de dignidade." Esse documento legal dispõe também sobre as obrigações do Estado e da família de garantir o seu pleno desenvolvimento, com destaque para o artigo 54, que versa sobre a responsabilidade do Estado de assegurar-Ihes o Ensino Fundamental, e para o inciso III do mesmo artigo, que estabelece para o Estado a obrigação de oferecer "atendimento educacional especializado aos portadores de deficiência, preferencialmente na rede regular de ensino", e o "acesso aos níveis mais elevados do ensino, da pesquisa e da criação artística, segundo a capacidade de cada um".

A Lei de Diretrizes e Bases da Educação Nacional (1996) estabelece, no artigo 58, que a Educação Especial deve ser uma "modalidade de educação escolar, oferecida preferencialmente na rede regular de ensino, para educandos portadores de necessidades especiais...; haverá serviços de apoio especializado ... [é] dever constitucional do Estado, tem início na faixa etária de zero a seis anos, durante a Educação Infantil".

A promulgação das declarações e leis gerais descritas anteriormente resultou na publicação de documentos regulamentadores e orientadores, dentre os quais citamos a Lei $\mathrm{n}$. $7.853 / 1989$, que

Dispõe sobre o apoio às pessoas portadoras de deficiência, sua integração social, sobre a Coordenadoria Nacional para Integração da Pessoa Portadora de Deficiência - Corde, institui a tutela jurisdicional de interesses coletivos ou difusos dessas pessoas, disciplina a atuação do Ministério Público, define crimes, e dá outras providências (Ministério da Educação, 2007).

O Decreto n. 3.298/1999 regulamenta a Lei n. 7.853/1989; a Lei n. 10.172/2001 "aprova o
Plano Nacional de Educação para Todos, que estabelece objetivos e metas para a implantação de programas que atendam às necessidades das pessoas com deficiência." Neste Decreto a Educação Especial é definida "como modalidade transversal a todos os níveis e modalidades de ensino, enfatizando a atuação complementar da Educação Especial ao ensino regular" (Ministério da Educação, 2007).

O Decreto n. 3.956/2001 "promulga a Convenção Interamericana para a Eliminação de Todas as Formas de Discriminação contra as Pessoas Portadoras de Deficiência." Sua adoção teve como principal objetivo o respeito aos direitos e liberdades fundamentais da pessoa com deficiência na mesma escala que as demais e a diminuição das barreiras que impedem a sua escolarização (Ministério da Educação, 2007).

A Resolução CNE/CEB n. 02/2001 instituiu as "Diretrizes Nacionais para a Educação Especial na Educação Básica”, que manifesta o compromisso do País com "o desafio de construir coletivamente as condições para atender bem à diversidade de seus alunos" (Ministério da Educação, 2007).

O Decreto n. 5.626/2005 regulamenta a Lei 10.436, que "dispõe sobre a Língua Brasileira de Sinais - LIBRAS, garantindo às pessoas com surdez o direito a educação através do ensino simultâneo de Língua Portuguesa e LIBRAS", e a Portaria n. 976/2006, que estabelece "Critérios de acessibilidade aos eventos do Ministério da Educação - MEC", assegurando padrões de acessibilidade (Ministério da Educação, 2007).

A implementação do Programa de Desenvolvimento da Escola - PDE decorreu da publicação do Decreto n. 6.094/2007, que "Dispõe sobre a implementação do Plano de Metas Compromisso Todos pela Educação" e garante $o$ acesso e permanência no ensino regular e $o$ atendimento às necessidades educacionais especiais dos alunos, fortalecendo seu ingresso nas escolas públicas (Ministério da Educação, 2007).

Em 2007 foram editados o Decreto $n$. 6.215/2007, que "institui o Comitê Gestor de Políticas de Inclusão das Pessoas com Deficiência - CGPD", revogado pelo Decreto 7.612/2011, que "institui o Plano Nacional dos Direitos da Pessoa com Deficiência - Plano Viver sem Limite" - e o Decreto n. 6.214/07, que "regulamenta o benefício de prestação continuada da assistência social devido à pessoa com deficiência." 
O Decreto n. 186/2008 aprovou "o texto da Convenção sobre os Direitos das Pessoas com Deficiência e de seu Protocolo Facultativo." No mesmo ano foi editado o Decreto n. 6.571/2008, que "dispõe sobre o atendimento educacional especializado", mas este foi revogado pelo Decreto n. 7.611, de 17/11/2011, que "dispõe sobre a Educação Especial, o atendimento educacional especializado e dá outras providências."

O que pretendemos demonstrar é o processo já percorrido no sentido de garantir direitos, promover acessibilidade, diminuir as barreiras institucionais para a inclusão de todos na sociedade, a qual precisa reconhecer e assumir efetivos posicionamentos para a diminuição das práticas de exclusão - o que não garante a mesma estrutura fora do papel.

\section{INCLUSÃO E PRECONCEITO: CONTEXTO}

Apesar das proposições filosóficas estruturadas no decorrer da história, a prática identificada no cotidiano escolar se apresenta de maneira diferente, de forma que os gestores, as famílias, os educadores e a comunidade escolar adotam seus próprios paradigmas na concepção da deficiência, o que gera diversas ações, entre elas a tentativa de normatização dos alunos, o agrupamento destes em classes especiais e a culpabilização mútua. Tais práticas fazem parte do ideário da inclusão, segundo o qual os alunos devem corresponder ao padrão esperado, e com esta atitude fazem emergir 0 preconceito enraizado, por lhes faltarem as informações necessárias para lidar com a situação, o que resulta na negação do problema e reforça ainda mais a dicotomia da normalidade versus anormalidade. Como afirma Machado (1994, p. 75), "muito já se tem criticado as práticas que produzem homogeneização, que trabalham com modelos, que restringem a diversidade e a diferença ao campo do normal e do anormal." A autora conclui que "a velha estratégia de juntar os homogêneos para resolver algum problema serve mais para produzir cristalizações do que imprimir algum movimento ao que está cristalizado."

Podemos afirmar que os grupos se organizam visando a objetivos e finalidades mediatizados por uma cultura baseada em costumes, valores, crenças, condutas e linguagem próprios. Uma interpretação equivocada da necessidade de cumprir regras em uma harmonia que não é capaz de existir, quando a solução de problemas pressupõe uma ação política de seus integrantes, pode desenvolver forte tendência a classificar seres que se adaptam com mais ou menos facilidade. Aqueles que apresentam limitações a esta adaptação são considerados desviantes, configurando-se como uma ameaça à obtenção de resultados satisfatórios conquistados sem a presença de conflitos.

A discussão sobre a inclusão escolar pressupõe refletir sobre o seu contrário. Só há o incômodo em relação a uma mudança para incluir pessoas porque, de alguma forma, estas estão segregadas, por motivos e explicações que foram historicamente construídos. Se de um lado há um anseio por incluir, é porque de outro lado existem os excluídos. Isto é tratar diferentes como iguais.

Ao discorrer sobre imposição de normas sociais às pessoas estigmatizadas como condição necessária para a vida social, Goffman (1963/1988) afirma:

O fracasso ou o sucesso em manter tais normas têm efeito muito direto sobre a integridade psicológica do indivíduo. Ao mesmo tempo, o simples desejo de permanecer fiel à norma - a simples boa vontade - não é o bastante, porque em muitos casos o indivíduo não tem controle imediato sobre o nível em que se apoia a norma. Esta é uma questão da condição do indivíduo, não da sua vontade (p. 138).

Ao analisarmos o contexto escolar, o que podemos perceber é que os antigos paradigmas fundantes da Educação Especial (a institucionalização e normatização) ainda não foram superados. As políticas públicas precisam avançar no sentido de assegurar aos educadores, às famílias e à comunidade escolar informações sobre as conquistas obtidas.

Outro aspecto importante na análise da questão da deficiência na sociedade atual é o preconceito baseado em juízos de valor, conforme apontam Collares e Moysés (1996):

Uma das características fundamentais da vida cotidiana é a existência de juízos provisórios, provisório porque se antecipa à atividade possível e independente do confronto com a realidade; nem sempre é confirmado, 
sendo muitas vezes refutado no infinito processo de prática. Quando um juízo provisório é refutado no confronto com a realidade concreta, seja por meio da ciência ou mesmo por não encontrar confirmação nas experiências da vida do indivíduo, e mesmo assim se mantém da razão; não é mais um juízo provisório, mas um preconceito (p. 25).

Uma das manifestações mais frequentes do preconceito é a atribuição de características inerentes aos alunos e suas famílias para justificar as dificuldades de aprendizagem usando-se como argumento a falta de condições físicas, intelectuais, emocionais e econômicas. Tal atitude dificulta sobremaneira o avanço no sentido de descobrir novas formas de educar, pois, na tentativa de resolver 0 que consideramos um pseudoproblema, os objetivos que de fato representam motivo de envolvimento ficam esquecidos.

A discussão que se apresenta é a de que, historicamente, as sociedades, apoiadas pelas ciências positivistas, lidaram com questões importantes de maneira naturalizante, reduzindo à condição humana os problemas sociais conflitantes e consequentemente de difícil solução, como mostra Bock (2002) quando enfatiza que "a ideia de uma natureza humana em cada um de nós" é uma concepção que encobre a história social humana (p. 14).

Com esta visão naturalizante, para classificar os indivíduos, especificamente, os alunos e os profissionais no interior das escolas, recorre-se ao psicólogo escolar, a quem geralmente é atribuída a tarefa de proceder aos diagnósticos que irão determinar o tratamento a ser oferecido, conforme a patologia apresentada.

No Brasil a Psicologia foi regulamentada como profissão em 1962. Nesse ano foram instituídos cursos de formação para psicólogos com estrutura baseada no modelo clínico. Este modelo vigorou até 1996, com formação teóricoexperimental completada por 500 horas de estágio, sendo indispensável a subordinação a imediata supervisão. Esta exigência resultou na interpretação de que os cursos de graduação deveriam necessariamente fundar uma clínicaescola. Estas ofereciam à população serviço de atendimento individualizado, comum à prática médica, o que pode ter contribuído para a cristalização do psicólogo como psicoterapeuta e a possibilidade de acesso das camadas populares a estes serviços, como escreve Silvares (2006).

Patto (2010) explica que a formação fundada na concepção clínica da Psicologia e sua relação com as instituições escolares deram-se inicialmente na área médica, pois eram os psiquiatras que se ocupavam de classificar a anormalidade dos "duros de cabeça" nos hospícios. Isto ocorreu por volta do final do século XVIII e início do século XIX, momento em que "as crianças que não acompanhavam seus colegas na aprendizagem escolar passaram a ser designadas como anormais escolares (destaques da autora) e as causas de seu fracasso procuradas em alguma anormalidade orgânica" (p.65).

Esta concepção sustentou a aplicação de testes para medir as capacidades intelectuais dos alunos com algum tipo de deficiência com ênfase na sua incapacidade, cristalizando o preconceito que vigora até os dias atuais. Neste sentido, a Psicologia foi (e tem sido) a ciência procurada para tentar avaliar a anormalidade destes escolares por meio da aplicação de testes.

Atualmente são inúmeras as demandas de pais, educadores, funcionários e alunos por questões relacionadas ao comportamento e às dificuldades de aprendizagem e relacionamento interpessoal. Diante da aparente esterilidade da Educação e da Psicologia, faz-se necessário compreender que estas são relações decorrentes do desenvolvimento histórico da humanidade. É preciso reconhecer que o homem é um ser equipado com potencialidades capazes não apenas de reproduzir, mas também de criar. A ausência de propostas coletivas e a prevalência de interpretações naturalizadas desta problemática carecem da compreensão de que somos aquilo que produzimos (Barroco, 2009). Por esta forma, entendemos que a articulação entre a Psicologia e Educação como ciências pode contribuir para novas formas de nos movermos na sociedade.

Acreditamos que as atribuições do psicólogo escolar (ou de qualquer outro profissional) não se reduzem a apenas diagnosticar a deficiência do aluno para classificá-lo e oferecer-lhe um tratamento ou classe específica, a exemplo das salas ou classes especiais, pois entendemos que a valorização, e até mesmo a exigência de diagnósticos e laudos, estabelecem limites de aprendizagem. Esta maneira de pensar e agir é contrária a uma política de educação 
humanizadora, que reconhece nos alunos o potencial que cada um apresenta para o alcance de suas próprias fronteiras e de sua formação escolar. Angelucci e Lins (2007) nos levam a refletir sobre os resultados da simplificação deste processo classificatório:

Partimos da ideia de que as características individuais têm que ser conhecidas para que um projeto pedagógico específico seja pensado para cada aluno, tendo em vista cada quadro psicopatológico. Com isso, voltamos a reproduzir - se é que algum dia deixamos de fazê-lo - a consagrada relação hierárquica entre psicologia e pedagogia. O diagnóstico clínico deve orientar o trabalho escolar. $E$ não se trata de qualquer diagnóstico, mas especificamente aquele que concebe o indivíduo como uma entidade patológica: procuramos e sempre encontramos, é claro, a falha (p. 343).

Independentemente das características individuais, cabe à escola transmitir os saberes necessários, isto é, as objetivações humanas e a busca de formas adequadas para este intento (Saviani, 2003). Concordando com esta elaboração, resgatamos a segunda e terceira teses de Marx (1991) sobre o pensamento de Feuerbach, as quais nos conduzem a pensar, respectivamente, que o pensamento humano não é uma questão puramente teórica, mas a realidade objetiva, e que, de acordo com a doutrina materialista, a alteração das circunstâncias se deve ao homem, que ao mesmo tempo se altera a si próprio em atividade. $\mathrm{O}$ autor se refere à atividade para definir os processos de trabalho, ou seja, a intervenção do homem sobre a natureza: à medida que a domina para suprir às suas necessidades, esse homem transforma a natureza e a si próprio.

Destarte, as demandas sociais se apresentam de maneira contraditória e em escala bastante elevada, sobretudo no que se refere ao contexto escolar, onde as relações se manifestam complexas e não há possibilidade de tratar os indivíduos distanciados da coletividade e de considerar o valor destas relações para o desenvolvimento individual e social. A análise da sociedade pode ser comprometida se o modelo clínico individualizante, anteriormente citado, for a opção adotada para ser aplicada nos sistemas escolares.

A escola não inicia a formação do sujeito, pois ao ingressar no sistema educacional ela já possui uma história anterior e está inserido em um espaço social e cultural no qual, através das relações, recebeu concepções e desenvolveu significados conforme seu grupo cultural, junto ao qual se apropriou de regras de conduta e paradigmas socialmente edificados, dentre estes, as formas de encarar a deficiência.

O detalhamento das discussões realizadas para institucionalização do acesso e permanência da pessoa com deficiência feito no início deste artigo mostra que as concepções que orientaram este processo foram delineadas historicamente, partindo do envolvimento político de famílias, educadores e demais profissionais insatisfeitos com o tratamento oferecido a esta parcela da sociedade, o qual não condizia com os ideais humanos desejados, por isso eram necessárias intervenções que modificassem este quadro. Tais movimentos nem sempre contaram com o consenso ou com discussões harmônicas, sem maiores conflitos ou espontaneamente.

Podemos traduzir que não há uma única forma ou uma forma mais adequada de resolver os problemas que envolvem pessoas com deficiência. Existe a possibilidade de pensar e agir com e para a coletividade. Isolar o fenômeno de todo o contexto que o produziu impede a análise crítica e afasta a possibilidade de criar novas metodologias para enfrentar a realidade dinâmica de cada indivíduo, dificultando o reconhecimento do próprio fenômeno como igualmente dinâmico.

\section{CONTRIBUIÇÕES DA PSICOLOGIA ESCOLAR CRÍTICA}

A Psicologia Escolar é uma área de atuação da Psicologia que, para o cumprimento de seu papel, necessita inserir-se na escola em articulação com outras ciências, entre as quais a Filosofia, a Filosofia da Educação e a Pedagogia, devendo apropriar-se de elaborações teóricas consolidadas para assumir o compromisso teórico-prático de se apropriar de recursos metodológicos que respondam às necessidades escolares (Meira, 2002).

O envolvimento na elaboração da proposta pedagógica e nas propostas de formação continuada de educadores e a participação efetiva na criação de novas metodologias de 
ensino podem fornecer ao psicólogo escolar informações importantes a respeito dos seus pares ou colegas de trabalho, dos alunos e suas famílias. Acrescentamos a estes tópicos o que consideramos mais valioso: o reconhecimento de que seres humanos são históricos e sociais, e não seres determinados apenas por sua condição natural.

Sobre a escola, Tada (2005) escreve que esse ambiente deve se constituir em um espaço de interações para "o desenvolvimento social do indivíduo" a partir da apropriação das regras, normas de conduta, conhecimento acadêmico e pensamento científico elaborados historicamente (p.156).

Acreditamos que Educação Especial, da mesma forma que a sociedade, é um processo fundado social e historicamente, por isto tomamos como referencial a Psicologia Histórico-Cultural a partir dos estudos de Vigotski, Luria e Leontiev, em questionamento à Psicologia naturalizante do ser humano, que enxerga o fenômeno psicológico desarticulado da realidade social.

Vigotski (1997) acredita que a investigação de crianças com deficiência deve-se dar por meio do estabelecimento de vias teóricopráticas. Para o autor, diante da tarefa de educar essas crianças a partir de diagnósticos, a Psicologia e a escola não lograrão êxito em uma perspectiva essencialmente teórica. As queixas das dificuldades devem ser confrontadas considerando-se a percepção dos pais, da instituição educacional e da própria criança. Embora a análise seja consolidada por meio de percepções, devem ser levadas em conta as reações objetivas da criança em relação ao mundo e as situações por ela vivenciadas, assim como a história do seu desenvolvimento.

Outro importante aspecto defendido por Vigotski (1997) na investigação é "a sintomatologia do desenvolvimento", que consiste em analisar, além dos aspectos clínicos, os "informes pedagógicos sobre o rendimento escolar, a preparação e educação da criança" (p. 21). A intenção é o estabelecimento de fatos para assim evitar um julgamento baseado apenas em suposições e feito "a custo da interpretação criativa dos sintomas" (p. 25).

A Psicologia pode contribuir com a escola no sentido de considerar os conhecimentos anteriormente elaborados pelos estudantes e seus valores gestados socialmente, para relacioná-los ao saber escolar. O psicólogo escolar deve inserir-se nas discussões pedagógicas e, em conjunto com os familiares e demais profissionais da escola, fomentar estratégias para a diminuição das barreiras atualmente impostas pela estigmatização de alunos com deficiência.

Vigotski (1997) afirma que "a educação especial deve ser subordinada ao social, deve ser coordenada com os parceiros sociais e, mais ainda, deve ser organicamente combinada com o social e penetrar no social como parte integrante" (p. 60).

Sobre a relação entre a Educação e a Psicologia como ciências, Barroco (2012) sugere a ampliação do debate sobre a educação que se pretende alcançar e o homem que se intenta formar. Afirma a autora:

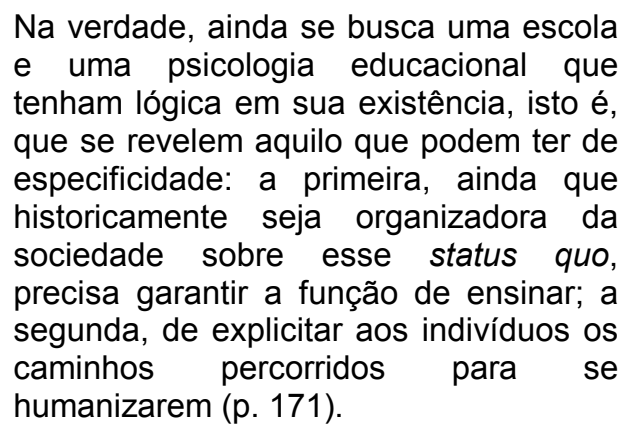

Por isso ressaltamos que, se a sociedade é estruturada de forma heterogênea, repleta de conflitos e contradições - que aliás, são fundamentais para o desenvolvimento social dos indivíduos que a compõem -, a escola e a Psicologia, neste contexto, têm motivos significativos para a superação de fatores limitadores que precisam ser desvelados, entre estes a questão do preconceito.

\section{CONSIDERAÇÕES FINAIS}

Se a educação para todos sugere incluir alunos sem qualquer tipo de distinção, podem os entender a necessidade de combater todas as formas de exclusão.

A partir deste estudo é possível depreender que tanto o acesso à escola e a permanência nela de pessoas com deficiência à escola, para que ali possam se apropriar do saber sistematizado, quanto a superação do preconceito e dos estigmas atribuídos em nome de uma normatização, devem advir de uma filosofia que fomente a interpretação da dialética inclusão/exclusão e dependem da superação 
coletiva das dificuldades de lidar com a problemática.

Analisamos que, embora os avanços tenham sido significativos no sentido de assegurar plenos direitos a todos os seres humanos, muito há que fazer para que a escola seja efetivamente um espaço democrático de participação social efetiva e de tomada de decisões. Para tanto, é necessário que os diversos atores sociais, partícipes das diversas instituições, sejam capazes de vencer os próprios preconceitos e consolidar novos paradigmas que favoreçam uma educação que promova a humanização dos indivíduos, ou seja, de uma educação em que todos tenham os seus processos de apropriação e objetivação do que já foi elaborado pelo gênero humano.

Da mesma forma que defendemos, no decorrer deste artigo, a impossibilidade de se analisar o homem dissociado do contexto histórico e social em que vive, asseveramos que as mudanças não ocorrem por força da natureza. Sobre este aspecto Saviani e Duarte (2012) chamam a atenção para as diversas contradições imanentes à educação atualmente oferecida pela escola na sociedade capitalista, entre elas a contradição existente na própria especificidade do trabalho educativo. Neste contexto, a socialização dos conhecimentos que, por serem constitutivos dos meios de produção, são os mais desenvolvidos, está sob o julgo do capital, que propõe a transposição de problemas de não aprendizagem dos integrantes da classe dominada para os consultórios médicos, assim como o esvaziamento de conteúdos na formação dos educadores e a atribuição à escola de múltiplas funções, as quais Ihe cerceiam a transmissão do conhecimento, ou seja, impedem-na de desempenhar a sua real função.

Entendemos que o atendimento escolar aos alunos com deficiência inclui a superação das contradições ocasionadas pelas lutas de classes, que valorizam os indivíduos apenas por aquilo que são capazes de produzir. Ignorar tais contradições resulta em fortes tendências à polarização dos problemas sociais. Tomamos por exemplo o que Duarte (2013) chamou de "ideologia apologética das diferenças" (p. 113), cujo reconhecimento da situação da inclusão de maneira dicotomizada leva os educadores, gestores até mesmo as famílias a tratarem os alunos de maneira idealizada, e não como realmente são.
A atual discussão acerca da inclusão escolar depende, sobretudo, do reconhecimento dos indivíduos como produto das relações históricas, buscando uma análise menos distanciada das condições sociais alienadas.

As contribuições da Psicologia Escolar crítica são de fundamental importância, pois levam ao reconhecimento dos alunos com deficiência como seres sociais e históricos, cujos ideais são erigidos de igual forma, com base na humanização de indivíduos através da convivência, da superação dos conflitos e da participação comunitária no trato com a informação e formação para a conquista da inclusão escolar.

\section{REFERÊNCIAS}

Angelucci, C. B., \& Lins, F. R. S. (2007). Pessoas significativamente diferentes e o direito à educação: uma relação atravessada pela queixa. In B.P. Souza. (Org.). Orientação à queixa escolar. (pp. 329- 349). São Paulo: Casa do Psicólogo.

Aranha, M. S. F. (2004). Educação inclusiva: a fundamentação filosófica. Brasília: Ministério da Educação, Secretaria de Educação Especial.

Barroco, S. M. S. (2009). Vigotski, arte e psiquismo humano: considerações para a psicologia educacional. In M. G. D. Facci, S. C. Tuleski, \& S. M. S. Barroco. (Orgs.), Escola de Vigotski: contribuições para a psicologia e a educação. (pp. 107-134). Maringá, PR: Eduem.

Barroco, S. M. S. (2012). A família fetichizada na ideologia educacional da sociedade capitalista em crise: uma questão para a Psicologia da Educação. In N. Duarte. (Org.), Crítica ao fetichismo da individualidade (pp. 151173). (2. ed. rev.). Campinas, SP: Autores Associados.

Bock, A. M. B. (2002). As influências do Barão de Münchhausen na Psicologia da Educação. In $\mathrm{E}$. Tanamachi, M. Proença, \& M. Rocha. Psicologia e Educação: desafios teórico-práticos (pp. 11-33). (2a ed.). São Paulo: Casa do Psicólogo.

Carvalho, S. R., \& Martins, L. M. (2011). A sociedade capitalista e a inclusão/exclusão. In: M. G. D. Facci, M. E. M. Meira \& S. C. Tuleski. (Orgs.). A exclusão dos "incluídos": uma crítica da psicologia da educação à patologização e medicalização dos processos educativos (pp. 17-35). Maringá, PR: Eduem.

Collares, C., \& Moysés, M. A. (1996). Preconceitos no cotidiano escolar: ensino e medicalização. São Paulo: Cortez.

Constituição da República Federativa do Brasil. (1988). Recuperado em 20 de julho, 2012, de http://www.senado.gov.br/legislacao/const/con1988/

Declaração de Salamanca. (1994). Sobre Princípios, Políticas e Práticas na Área das Necessidades Educativas Especiais. Recuperado em 12 de dezembro, 2011, de http://portal.mec.gov.br/seesp/arquivos/pdf/salamanca.pdf 
Declaração Mundial sobre Educação para Todos: satisfação das necessidades básicas de aprendizagem. Jomtien. (1990). Recuperado em 12 de dezembro, 2011, de http://unesdoc.unesco.org/images/0008/000862/086291po r.pdf

Declaração Universal dos Direitos Humanos. (1948). Assembléia Geral das Nações Unidas. Recuperado em 12 de dezembro, 2011, de http://portal.mj.gov.br/sedh/11cndh/site/pndh/sis int/onu/co nvencoes/Declaracao\%20Universal\%20dos\%200Direitos\% 20Humanos-\%201948.pdf

Decreto do Executivo n. 7.611/2011. (2011). Dispõe sobre a Educação Especial, o atendimento educacional especializado e dá outras providências. Diário Oficial da União, p. 12.

Decreto do Executivo n. 7.612 (2011). Institui o Plano Nacional dos Direitos da Pessoa com Deficiência - Plano Viver sem Limite. Diário Oficial da União, p. 12.

Decreto Legislativo n. 186. (2008). Aprova o texto da Convenção sobre os Direitos das Pessoas com Deficiência e de seu Protocolo Facultativo, assinados em Nova lorque, em 30 de março de 2007. Diário Oficial da União, Seção 1, Edição 131, p. 1.

Duarte, N. (2013). A individualidade para-si: contribuição a uma teoria histórico-social do indivíduo. (3. ed. rev. e ampl.). Campinas, SP: Autores Associados.

Goffman, E. (1988). Estigma: notas sobre a manipulação da identidade deteriorada. (M. B. Nunes, Trad.). (4. ed.). Rio de Janeiro: Guanabara. (Original publicado em 1963).

Lei n. 8.069/1990. (1990). Dispõe sobre o Estatuto da Criança e do Adolescente e dá outras providências. Diário Oficial da União, seção 1 .

Lei n. 9.394, de 20 de dezembro de 1996. (1996). Estabelece as Diretrizes e Bases da Educação Nacional. Diário Oficial da União, seção 1.

Machado, A. M. (1994). Crianças de classe especial: efeitos do encontro da saúde com a educação. São Paulo: Casa do Psicólogo.

Marx, K., \& Engels, F. (1991). A ideologia alemã: Feuerbach. (J. C. Bruni, \& M. A. Nogueira., Trad.). (8. ed.). São Paulo: Hucitec.

Meira, M. E. M. (2002). Psicologia Escolar: pensamento crítico e práticas profissionais. In E. Tanamachi, M. Proença, \& M.
Rocha. Psicologia e Educação: desafios teórico-práticos (pp. 35-71). (2. ed.) São Paulo: Casa do Psicólogo.

Ministério da Educação. (2007). Política Nacional de Educação Especial na perspectiva da Educação Inclusiva. MEC: Brasília - DF.

Patto, M. H. S. (2010). A produção do fracasso escolar: histórias de submissão e rebeldia. (3. ed.). São Paulo: Casa do Psicólogo.

Saviani, D. \& Duarte, N. (2012). Pedagogia histórico-crítica e luta de classes na educação escolar. Campinas-SP: Autores Associados.

Saviani, D. (2003). Pedagogia histórico-crítica: primeiras aproximações. (8a ed. rev. e ampl.). Campinas-SP: Autores Associados.

Secretaria de Educação Especial (2006). Direito à educação: subsídios para a gestão dos sistemas educacionais: orientações gerais e marcos legais. (2. ed.). Brasília, MEC: Organização: BLATTES, R. L.

Silvares, E. F. M. (2006). Clínica-Escola: Integração da formação acadêmica com as necessidades da comunidade. In E. F. M. Silvares. (Org.) Atendimento Psicológico em Clínicas-escola (pp. 10-21). Campinas, SP: Alínea.

Tada, I. N. C. (2005). Dialogando com Amanda: contribuições da teoria histórico cultural na compreensão de uma jovem com síndrome de Down. Tese de Doutorado, Instituto de Psicologia, Universidade de São Paulo, São Paulo.

Tada, I. N. C. (2009). Os desafios de atuação do psicólogo escolar: da educação especial à educação inclusiva. In A. T. Souza, A. M. Lima (Org.). Psicologia, saúde e educação: desafios na realidade Amazônica (pp. 61-83). São Carlos-SP: Pedro e João.

Vigotski, L. S. (1997). Obras Completas V. Fundamentos de defectologia. Habana: Editorial Pueblo y Educación.

Recebido em 09/08/2012 Aceito em 15/07/2014

Marasella del Cármen Silva Rodrigues Macedo: pedagoga, formada pela Universidade Federal de Rondônia e mestranda pelo Programa de Pós-Graduação em Psicologia na mesma universidade.

Deusodete Rita Silva Aimi: pedagoga, formada pela Universidade Federal de Rondônia e mestranda pelo Programa de Pós-Graduação em Psicologia na mesma universidade.

Iracema Neno Cecilio Tada: doutora em Psicologia Escolar e do Desenvolvimento Humano pela Universidade de São Paulo, professora associada da Universidade Federal de Rondônia, Brasil.

Ana Maria de Lima Souza: doutora em Psicologia Escolar e do Desenvolvimento Humano pelo Instituto de Psicologia da Universidade de São Paulo, professora associada da Universidade Federal de Rondônia, Brasil. 